\title{
C-39 HABITAT AND EXPLORATION POTENTIAL OF THE ULTRA-DEEPWATER OFFSHORE MEDITERRANEAN
}

A. ABDEL AAL, A. EL BARKOOKY, M. GERRITS, H. MEYER, M. SCHWANDER and H. ZAKI

Shell Egypt Deepwater B.V., Egypt

\begin{abstract}
The Northeast Mediterranean Deepwater Block lies in water depths of $800 \mathrm{~m}$ to $2800 \mathrm{~m}$ in front of the Nile Delta Cone. The Block is exceptional for its size $\left(41,500 \mathrm{~km}^{2}\right)$, roughly equal to the total area presently licensed over the Nile Delta, which to date has yielded dry gas and gas/condensate. The structural and stratigraphic setting of the block offers a variety of hydrocarbon trapping possibilities similar to the deepwater settings of other productive deltas. This venture falls in the category of real frontier exploration opportunity.
\end{abstract}

The NE Mediterranean Block was awarded to Shell Egypt in late 1998 against strong international competition in recognition of Shell's leading expertise in deepwater evaluation and development. Shell Egypt offered 25\% interest to Exxon/Mobil Exploration and Production Egypt limited in late 1999.

A regional 2D seismic programme of some $7000 \mathrm{~km}$ of seismic data was acquired in early 1999 , covering most of the area for the first time and recording sedimentary sequences down to 8 seconds. This program was followed by an extensive 3D seismic survey of $7000 \mathrm{~km}^{2}$. After acquisition of the $2 \mathrm{D}$ seismic data, work focussed on defining different petroleum systems by integrating seismic data with newly acquired gravity and aeromagnetic data. Emphasis was placed on reservoir distribution and charge modelling, with main objectives identifying high prospectivity trends and of valuing the acreage.

The Plio-Pleistocene sequence is considered to be the prime target in the NE Mediterranean UltraDeepwater Block, which is interpreted to cover a slope to basin floor setting. Basin-fill models calibrated by detailed sequence stratigraphic analysis in the explored part of the Nile Delta predict a variety of turbidite environments. Syn-depositional fault movement and mobile salt created confined turbidite settings with the development of mini-basins and local sediment-ponding, particularly in the east of the acreage. These settings coexist with a graded-slope to the west, where unconfined turbidite deposition occurred in slope channel systems.

Four distinct geological domains have been identified, each with significantly different structural and stratigraphic characteristics and different hydrocarbon play opportunities. On the Platform, PlioPleistocene deepwater channel and basin floor turbidite sands are trapped in a variety of structural settings (as proven by recent discoveries located south of the block such as Rosetta, Saffron and Scarab wells). Channels cross four-way closures or structural noses in the relatively unstructured platform area. Seismic lines show the widespread presence of amplitude anomalies at various, stacked levels throughout the Pliocene section.

The Upper Miocene sequence offers exploration objectives in the form of shallow to deep marine sands, deposited in platform, canyon and canyon-front settings. This play is well 
established further inboard, where a number of structures have yielded gas deposits in the 1-3 TCF range. Prospects consist of subtle closures within a large Messinian canyon. Additional, so far untested potential is thought to exist in the deeper water in front of the canyon, where sheet sands appear to abutt against salt diapirs.

The eastern part of the block is characterized by the development of a diapiric salt basin as a result of salt movement and salt withdrawal. This area was influenced by major structuration attributable to the intersection of major NW-SE and NE-SW strike slip faults. Seismic indicates the presence of sheet sands as well as local channels. Slicks attest to oil charge along major strike-slip faults and through salt windows. Pre-salt exploration of distal turbidites within the Serravalian to Tortonian sequence and the identification of new reservoir sequences deposited over and along pre-existing intra-basinal highs add to the prospectivity in this area.

In the Northwest part of the block, the southern limit of the Messinian Salt Basin is marked by the by the presence of major East-West oriented rotated fault blocks. These resulted from the nortward displacement of salt with Pliocene sedimentation. The up-thrown fault blocks form a major prospective element in the area. Amplitude support attests to the likely presence of gas and/or oil charge in thin, more distal (channelised) sheet sand reservoirs.

Figures

1. Figure-1 NE Mediterranean deepwater location map.

2. Figure-2 NE Mediterranean deepwater block database map, illustrating the Nile Delta wells, discoveries, deep-sea drilling project shallow wells and Shell 1999-2D seismic survey.

3. Figure-3 Nile Delta cone and ultra-deepwater geological domain map.

4. Figure-4 Pliocene depositional system along the Nile Delta cone and the ultra-deepwater area.

5. Figure-5 Upper Miocene (Messinian) depositional system along the Nile Delta cone and the ultradeepwater area.

6. Figure-6 Evidence for hydrocarbon charge from DHI's, gas. chimneys and slicks along the NE Mediterranean deepwater block.

Please note that this abstract has been retyped and the figures are scanned, as it was not received in a digital format. EAGE cannot be held responsible for any typing errors that may occur nor for any results that might arise from scanning the figures in this text. 


\section{NE Mediterranean Deepwater Area}
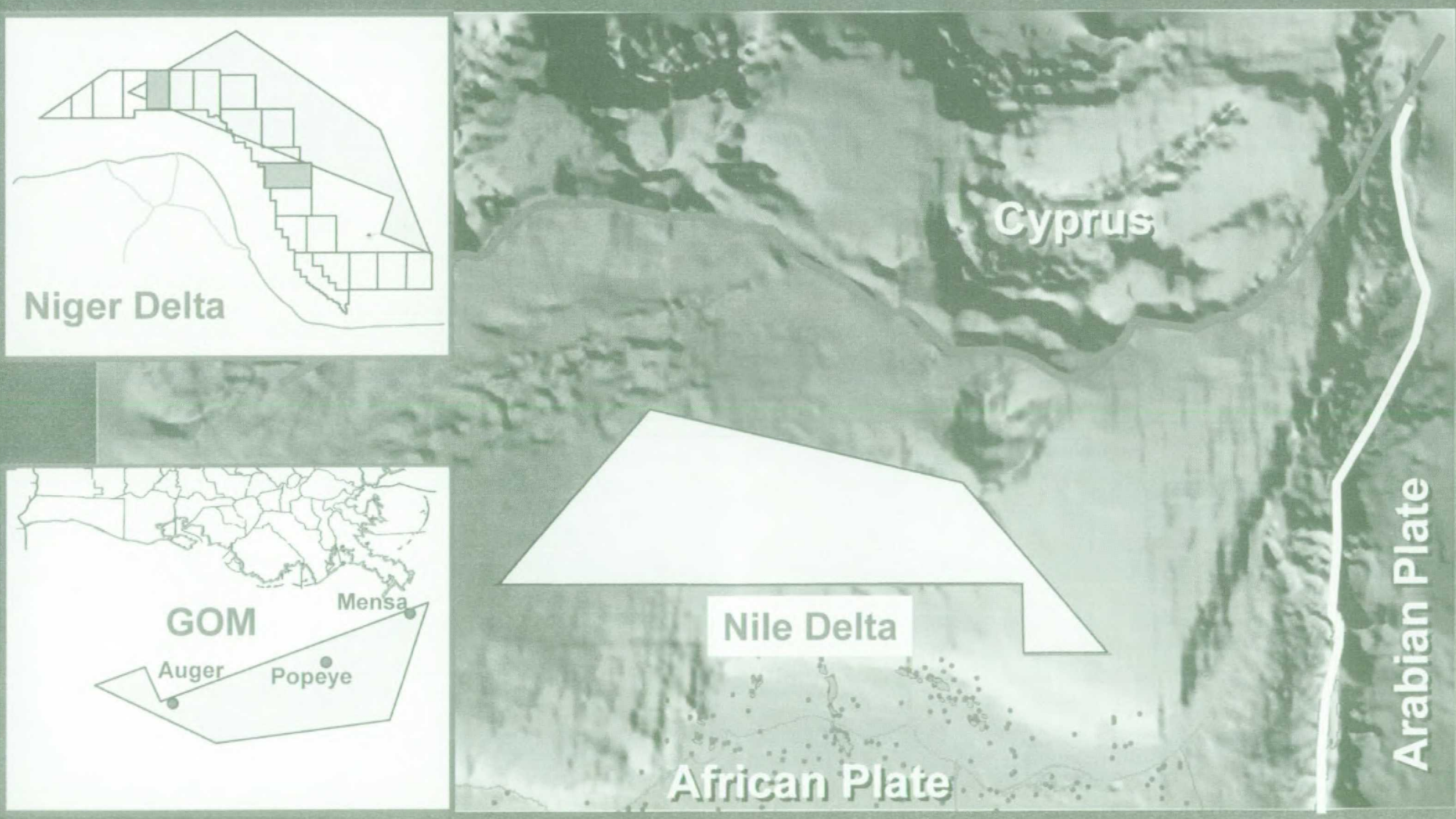

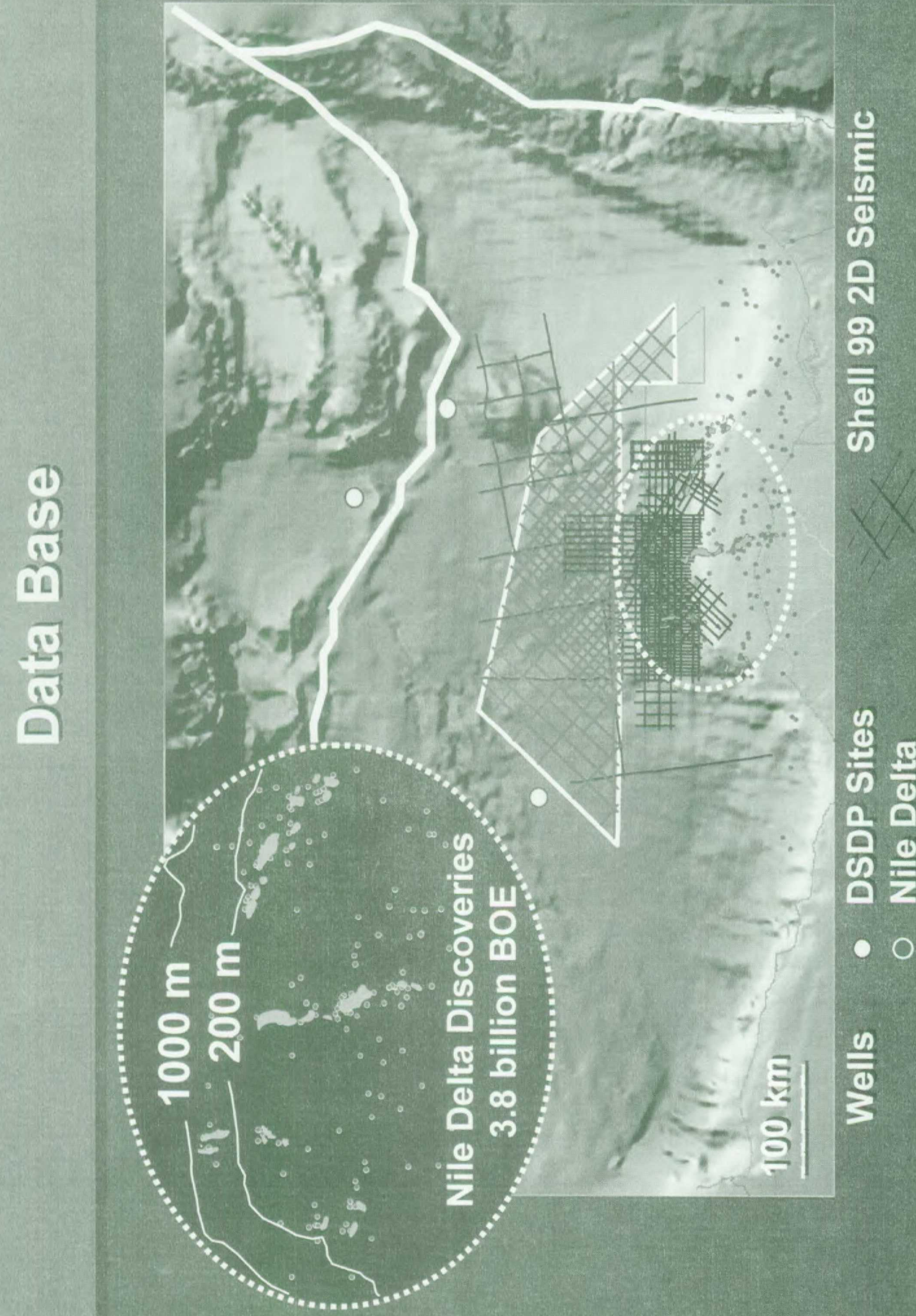


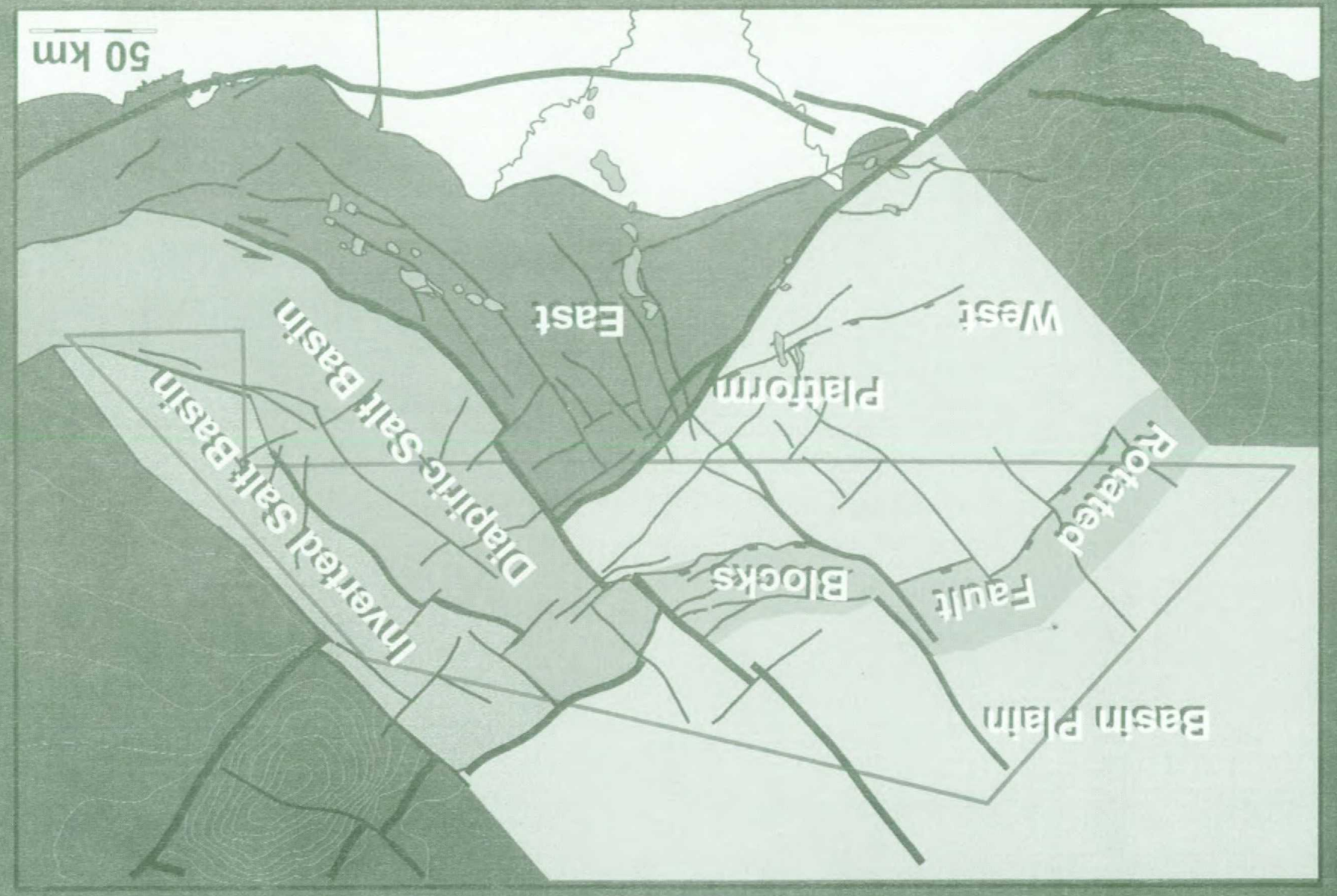

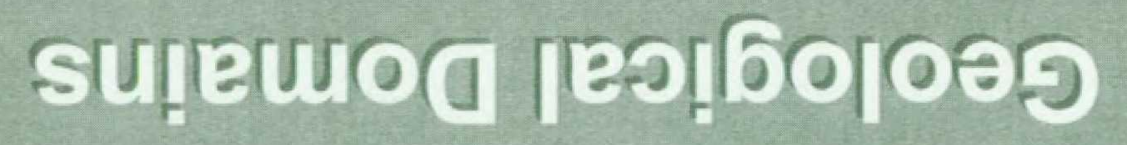




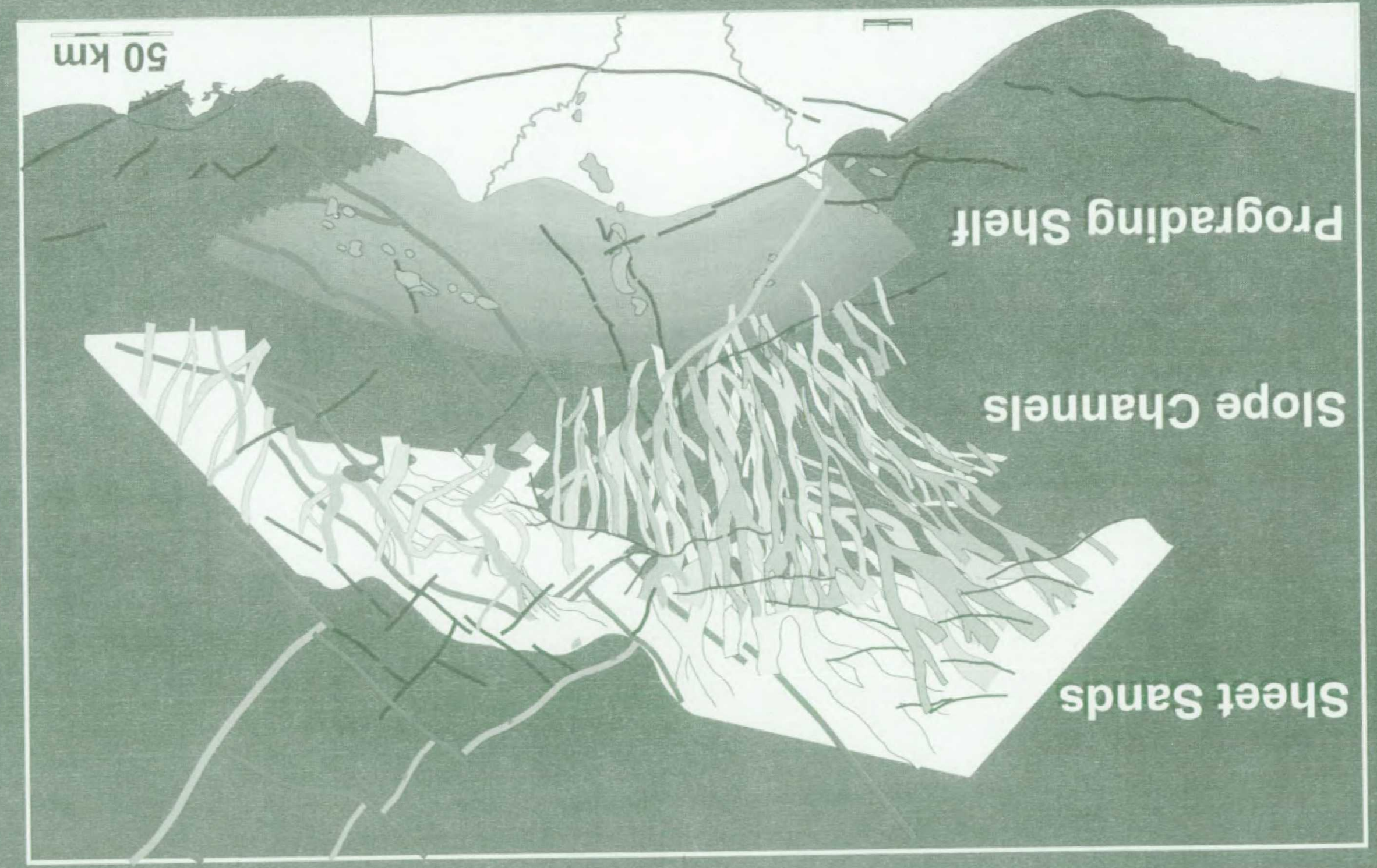

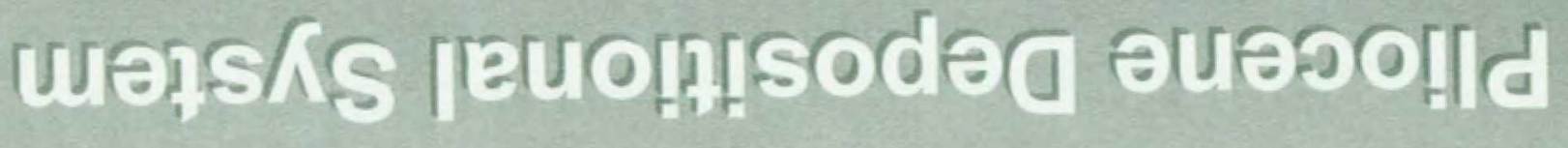




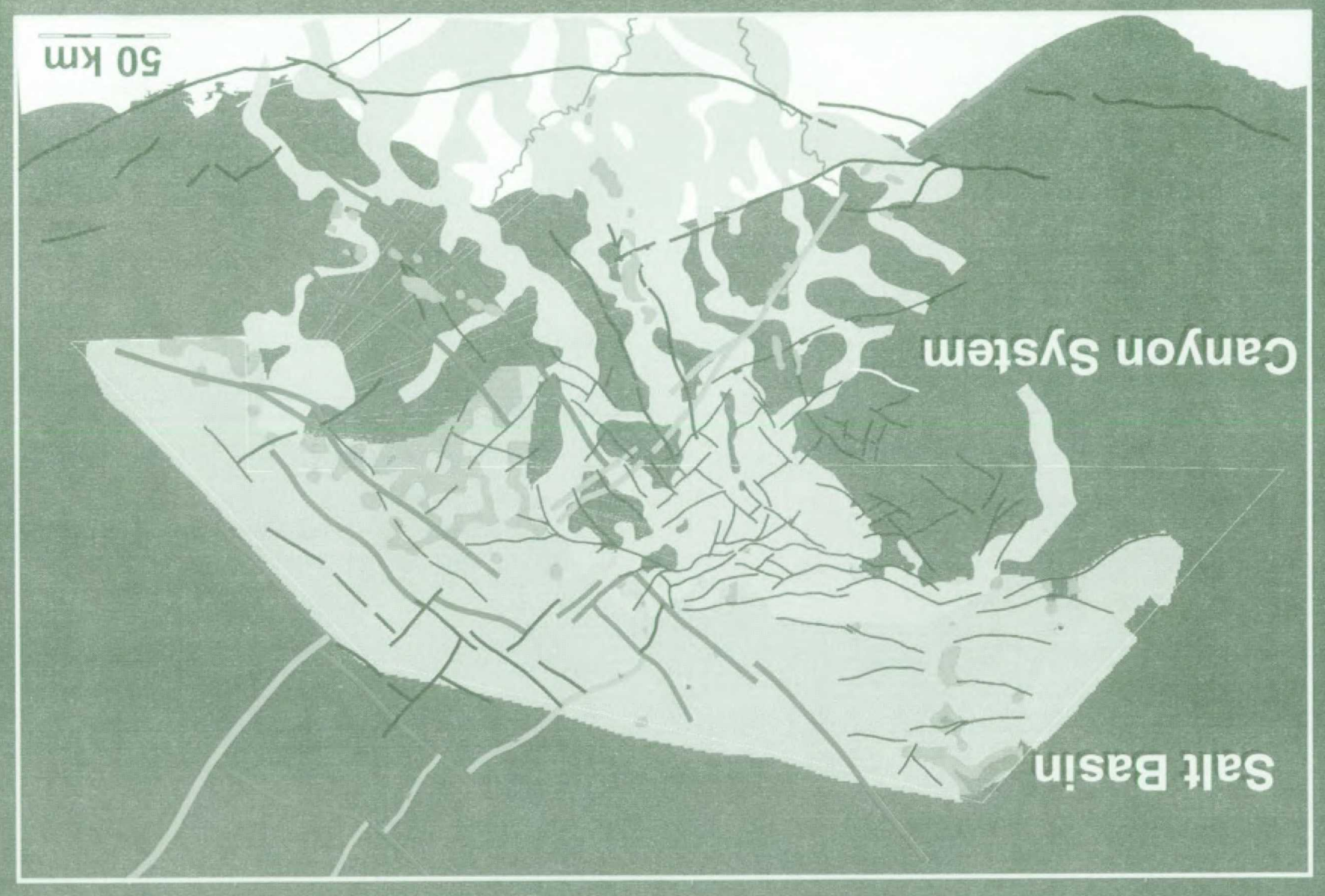

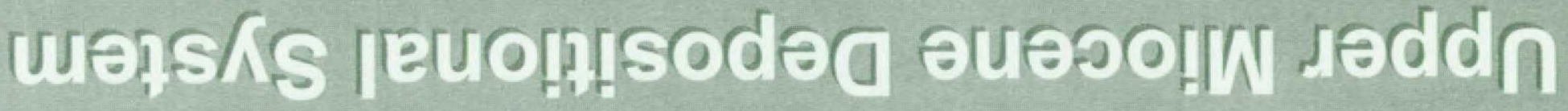


